\title{
El trabajo de la judicatura laboral: directrices legales, colaboración y afectos
} The work of labor law: legal guidelines, collaboration and affections

\author{
Iván Esteban Grudechut Pezoa \\ Universidad Alberto Hurtado
}

\section{Resumen}

El derecho laboral chileno es una institución construida con el objetivo inicial de mediar y equilibrar la relación entre trabajadores y empleadores. ¿Se logra este objetivo? Se analiza este problema desde la experiencia laboral de los jueces en relación con la tarea que tienen dispuesta. Este es un estudio etnográfico que se enmarca desde la Teoría del Actor-Red. El trabajo de campo se realiza en el primer y segundo juzgado laboral de Santiago de Chile. Como principal resultado, se observa que existe una tendencia a la conciliación, la cual refiere a que hay una compleja red de actantes que fomentan la producción de conciliaciones. Esta red se sostiene en leyes, actores y afectos. Esto es un problema, pues hay toda una serie de juicios que pudiendo terminar favoreciendo a la parte empleada, lo hacen forzando conciliaciones que evitan la realización del espíritu inicial del derecho laboral.

Palabras clave: Etnografía Judicial; Derecho al trabajo; Jueces; Antropología Cultural

\begin{abstract}
Chilean labor law is an institution built with the initial objective of mediating and balancing the relationship between workers and employers. Is this objective achieved? This problem is analyzed from the work experience of the judges in relation to the task they have arranged. This is an ethnographic study is framed from the Actor-Network Theory. The field work is carried out in the first and second labor courts of Santiago de Chile. As the main result, it is observed that there is a tendency to conciliation, which refers to the fact that there is a complex network of actants that promote the production of conciliations. This network is supported in laws, actors and affects. This is a problem, since there is a whole series of lawsuits that may end up favoring the employed party, end up forcing conciliations that prevent the realization of the initial spirit of labor law.
\end{abstract}

Keywords: Judicial Ethnography; Right to work; Judges; Cultural Anthropology 


\section{INTRODUCCIÓN}

El derecho laboral chileno -en tanto institución especializada- nace y se desarrolla desde las presiones que la clase trabajadora le puso a la clase empleadora (Valenzuela, 2008). En 1921, para regular las movilizaciones de la cuestión social, se comienza a elaborar el Código del Trabajo (Valenzuela, 2008), el cual supone ser una ley elaborada para proteger a la clase trabajadora de la clase empleadora.

Una vez promulgado, el Código del Trabajo (CT de ahora en adelante) se establece como la ley protagónica al momento de resolver contiendas laborales. Sin embargo, no es el único hito que nos interesa. Desde el 2009, se implementó la reforma procesal laboral. Esto implicó construir tribunales especializados en el derecho laboral, ajustarse a los más modernos sistemas imperantes y agilizar la solución de los conflictos, evitando la tensión de largas tramitaciones (Montt, 2016). Esto implicó instalar infraestructura para que el trabajo de los jueces y juezas con las partes fuese principalmente oral, así como también se le retiraron tareas administrativas a los jueces. De este modo, sobre los jueces y juezas recae poner énfasis en el trabajo judicial, el cual es entendido como resolver conflictos entre partes, y no encargarse de la administración de los tribunales (Vargas, 2007). ¿Cómo viven los jueces y los demás trabajadores la nueva forma que adopta el trabajo judicial?

Modelos para evaluar el comportamiento de los jueces y juezas tienen su historia. Lee Bernick y David Pratto (1995) desarrollan un sistema llamado "Evaluación de Rendimiento judicial", el cual es seguido en los estudios de David Brody en el 2000 y en el 2008-2009. Este sistema se enfoca ante todo en el funcionario judicial individual y su comportamiento, abarcando sus actividades y conducta hacia otros, especialmente en la sala del juzgado (Roach Anleu y Mack, 2016). Si bien es justificable analizar este aspecto, realizar un análisis del comportamiento judicial, sólo desde un enfoque individualista, es claramente insuficiente. La acción de un agente necesita ser comprendida en relación al contexto en el que está. Sobre esto, Gibson señala que "el rendimiento judicial y la conducta judicial ocurren en un escenario compuesto por requerimientos institucionales, estructuras organizacionales, prácticas y expectativas locales y variedad diaria e imprevisibilidad en los casos, así como condiciones sociopolíticas más amplias" (Gibson 1980, en Roach Anleu y Mack, 2016, p. 81).

Desde lo anterior, me pregunto ¿Cómo funciona la relación entre el contexto judicial laboral y la acción de los jueces y juezas? ¿La relación entre el contexto laboral y la acción de los jueces facilita el desarrollo de una defensa judicial con respecto a la población trabajadora? Analizaré empíricamente este problema desde la Teoría del Actor-Red (TAR de ahora en adelante), la cual es una 
teoría que permite mirar al sujeto en relación con las múltiples prácticas que lo rodean.

Desde ya, adelanto que la respuesta que encuentro a la pregunta es que se estructura una tendencia a la conciliación, la cual en ocasiones obstaculiza que los tribunales laborales puedan realizar el espíritu de la ley laboral. Para dar cuenta de esto, la TAR establecerá diálogos con la crítica al Nuevo Management y una lectura de la filosofía de Kierkegaard.

\section{SOBRE LA TEORÍA DEL ACTOR-RED}

En este apartado, trataré las nociones básicas de la TAR, para luego abordar cómo entender al cuerpo humano en esta teorización. Bruno Latour es uno de los principales exponentes de la TAR. La redacción de su versión de esta teoría se encuentra en "Reensamblar lo social" (Latour, 2005/2008) y su utilización en contextos judiciales se encuentra en "Haciendo el derecho" (Latour, 2002/2010). Esta teoría parte del supuesto de que "lo social no designa algo entre otras cosas, como una oveja negra entre ovejas blancas, sino un tipo de relación entre cosas que no son sociales en sí mismas." (Latour, 2005/2008, p. 19). Este supuesto es relevante, pues, con base en él, Latour sostendrá que para hacer investigación acerca de lo social no hay que ir a ver cómo actúa un objeto específico, sino que es necesario indagar acerca de cómo se asocian los objetos (Latour, 2005/2008). De este modo, "lo social" refiere a una serie de interconexiones entre elementos que sostienen lo que ocurre en un contexto de prácticas.

Si seguimos este argumento, podemos preguntarnos ¿A qué se refiere Latour con "cosas" que se asocian entre sí? Claudio Ramos (2008), a propósito de estudiar a la ciencia, señala que para entender la noción de "elemento", necesitamos entender en qué sentido esta es una teoría "del Actor-Red". Un actorred refiere a "elementos heterogéneos, humanos y no humanos, conectados temporalmente, para producir, en el caso de la ciencia, hechos científicos" (p. 37). Es decir, "cosas" refiere a preguntarse concretamente por los distintos elementos que participan para sostener un hecho social contingente. Este hecho se mantiene en el tiempo por efecto de ser soportado por las acciones de un variado conjunto de elementos entramados, donde encontramos tanto la acción de humanos como de agentes no humanos. Típicamente, a estos elementos, se les llama "actantes". Por ejemplo, una audiencia judicial laboral chilena no puede ocurrir si no hay una grabadora de audio, o si no está el funcionario de sala que prende esa misma grabadora. Gran parte del "Poder Judicial" se soporta sobre la acción de estos actantes, normalmente invisibles para el ojo 
del visitante. De este modo, la red del derecho laboral se sostiene desde la acción conjunta de distintos elementos.

Sobre lo anterior, el actor-red no es un objeto en sí, sino que, al ser una articulación de elementos, no tiene ni un principio ni un final. Desde ese punto, es relevante para el investigador seleccionar sobre qué aspecto enfatizar la observación de las redes, de acuerdo a los objetivos de su investigación (Ramos, 2008). En el caso de este artículo, nuestro actor-red se enfoca en la acción que rodea a los jueces y juezas.

En primera instancia, esta teorización sobre las redes es útil, pues "reconstruir estas redes tiene indudable valor explicativo" (Ramos, 2008, p. 38). Esto es porque, en la medida que uno pueda mostrar cómo operan ciertos agentes en relación a las prácticas estudiadas, entonces podremos dar cuenta de cómo funciona la construcción de la práctica misma, la construcción del "hecho social” (Latour, 2005/2008). Desde lo anterior, Latour (2005/2008) señalará insistentemente que se hace necesario describir las asociaciones, pues una buena descripción es una buena explicación.

Un aspecto importante de esta teorización es el de tomar en cuenta a un viejo objeto de la teoría social: el cuerpo. Según Arthur Arruda Leal Ferreira (2011), Latour entenderá que el cuerpo no es "una esencia, una substancia, sino [...] una interface que se torna más y más descriptible cuando se aprende a ser afectado por diversos elementos" (p. 197). Desde esta mirada, el cuerpo es un elemento que, al entramarse en una red de relaciones con otros agentes, comienza a afectarse. Esto promueve que el cuerpo aprenda las acciones que facilitan la adaptación a los elementos mismos, así como también permite dar cuenta de cómo se siente el cuerpo la acción de los elementos sobre él mismo. Esta faceta es relevante, porque nos permite entender que los cuerpos producen afecciones específicas en relación a las redes en que están circunscritos. Esto se emparenta con los estudios etnometodológicos de Harold Garfinkel (1968/2006), pues en estos se señala cómo la forma en que se construye la cotidianidad implica la construcción de expectativas orientadas al cumplimiento de éstas, disponiendo afectos tanto a propósito de llevar a cabo las expectativas socialmente construidas, así como se desarrollan otras si éstas no se cumplen.

Desde lo anterior, rescataremos estos dos aspectos claves para esta investigación: la concepción teórica de lo social y la forma en que el cuerpo es afectado por los efectos de los elementos entramados en la red de asociaciones. De este modo, abordaremos cómo se articula la red de actores humanos y no humanos que forman al derecho laboral. 


\section{METOdOLOGÍA}

Este artículo está orientado por la TAR. Esto quiere decir que el trabajo empírico está organizado para rastrear las asociaciones que dan cuenta del "hecho social" llamado "derecho laboral", poniendo énfasis en entender cómo jueces y juezas participan de esta red. Esto no quiere decir que el trabajo de funcionarios, abogados u otros actantes quedará fuera de la investigación, pero el énfasis no estará puesto en ellos.

Este artículo utilizará un enfoque etnográfico. Para Rosana Guber (2001/2011), un texto etnográfico es aquel que "intenta representar, interpretar o traducir una cultura o determinados aspectos de una cultura para lectores que no estén familiarizados con ella." (p. 21). Por causa de lo anterior, se hizo necesario implementar una serie de técnicas que permitan producir información que dé cuenta de la cultura del lugar escogido. Esto se condice con la principal característica de la etnografía. El etnógrafo participa "haciendo acopio de cualquier dato disponible que sirva para arrojar un poco de luz sobre el tema en que se centra la investigación" (Hammersley y Atkinson, 1994, p. 15). La cultura es un fenómeno complejo, y por tanto la utilización de distintos medios para poder dar cuenta de este objeto es un mínimo necesario.

Para comenzar el proceso investigativo, inicio yendo a las audiencias públicas, entrando a diversos juicios, dado que es en este lugar donde se concentran varios de los actores que participan de los procesos judiciales (partes, abogados, jueces, encargados de sala, testigos, computadores, grabadoras, micrófonos, podios, martillos, etc.). Desde esta observación inicial, voy indagando sobre cómo estos establecen sus relaciones con la audiencia misma. El análisis de estas diversas relaciones marca la complejidad de procedimientos que exige la etnografía para dar cuenta de la construcción del derecho laboral. En la tabla 1 mostraré un cuadro que resume los procedimientos utilizados en este artículo.

\begin{tabular}{|c|c|}
\hline Procedimiento & Descripción del procedimiento \\
\hline \multirow{2}{*}{$\begin{array}{l}\text { Observaciones } \\
\text { de audiencias y } \\
\text { pasillos }\end{array}$} & $\begin{array}{l}\text { Observaciones de audiencias judiciales: } 77 \text {. (Mezcla audiencias preparatorias y de jui- } \\
\text { cio). }\end{array}$ \\
\hline & Observaciones de pasillo: 26 ocasiones que, en promedio, duraron 30 minutos. \\
\hline $\begin{array}{l}\text { Análisis de } \\
\text { Documentos }\end{array}$ & $\begin{array}{l}\text { Se revisaron los documentos de cada uno de los casos vistos, se adquirieron a través } \\
\text { de la página web del Poder Judicial o fueron señalados por agentes judiciales. }\end{array}$ \\
\hline $\begin{array}{l}\text { Análisis de da- } \\
\text { tos estadísticos }\end{array}$ & $\begin{array}{l}\text { Se revisó la base de datos del Poder judicial, los cuales son públicos a propósito de las } \\
\text { nuevas políticas de transparencia. }\end{array}$ \\
\hline $\begin{array}{l}\text { Entrevistas } \\
\text { etnográficas }\end{array}$ & $\begin{array}{l}10 \text { entrevistas hechas a jueces/as, funcionarios/as de sala, trabajadores/as, aboga- } \\
\text { dos/as de la parte demandante y abogados/as de la parte demandada. }\end{array}$ \\
\hline $\begin{array}{l}\text { Etnografía } \\
\text { revisitada }\end{array}$ & $\begin{array}{l}\text { Se revisaron dos etnografías realizadas previamente en los juzgados laborales chile- } \\
\text { nos. }\end{array}$ \\
\hline
\end{tabular}

Tabla 1. procedimientos utilizados en la etnografía 
Dentro de las herramientas a usar, destaca la etnografía revisitada. Esta técnica permite "extraer lo general de lo único, pasar de lo 'micro' a lo 'macro' y conectar el presente con el pasado en vistas del futuro, todo a partir de una teoría preexistente" (Burawoy, 1998, p. 5). Desde lo anterior, se revisarán dos etnografías hechas en el pasado para contrastarla con el presente, y así poder tener una visión general del devenir del derecho laboral.

El trabajo de campo de esta investigación data su inicio en agosto del 2018 y llega hasta enero de 2020. Los lugares en que se hizo este trabajo son el Primer y Segundo Tribunal Laboral de Santiago de Chile.

Con respecto a la escritura de los resultados - a diferencia de Latour (2002/2010), quién recién en el último capítulo de su investigación establece un diálogo entre lo descrito y las teorizaciones acerca de lo judicial- en este texto intentaremos realizar una etnografía en que el diálogo con la teorización se desarrolle en conjunto con la descripción. Esto está inspirado en el trabajo de Leticia Barrera (2012), quién escribe de este modo en su etnografía de la Corte Suprema argentina. En este caso, se asume esta segunda opción como más pertinente, pues el formato "paper" es más pequeño que el formato "libro".

Es importante señalar algo más. Dado que la cantidad de jueces y encargados de sala de los tribunales laborales no son una población grande, he decidido que no daré cuenta del género de las personas en cuestión. En cambio, de abogados y trabajadores si se dará cuenta del género, pues estos son una población flotante mucho más difícil de identificar. Por supuesto, esto es un defecto para poder investigar temáticas asociadas al género, pero es relevante volver menos identificable -en términos éticos- a los distintos actores observados.

Finalmente, es importante decir que los entrevistados y entrevistadas firmaron un consentimiento informado, en el cual se daba cuenta del nombre del proyecto, cuál era su objetivo y que sus nombres o rasgos distintivos no iba a ser expuesto en ninguna publicación.

\section{RESULTADOS}

En este apartado mostraré los distintos resultados de la investigación. El primer resultado se basa en la lectura de las dos etnografías que se han realizado a propósito de las prácticas del derecho laboral en Chile. Estas son el trabajo de letswaart (1981) y el de César Rosado (2018). Luego, describiré brevemente cómo ocurre en términos de tiempo y espacio el derecho laboral, para finalmente realizar un análisis de la experiencia, configurando lo que llamé "la tendencia a la conciliación". 


\section{La historia de las prácticas. Etnografías en los tribunales del trabajo}

De acuerdo a la etnografía revisitada (Burawoy, 1998), daré cuenta de dos artículos etnográficos realizados en tribunales, los cuales servirán como contraste a lo empíricamente observado en este estudio. El primero es un artículo llamado "Litigio de relaciones laborales: Chile, 1970-1972" de Heleen letswaart (1981). El segundo es llamado "El juez laboral desatado: Imperio de la Ley y Derecho laboral en Chile 'Neoliberal'” de César Rosado (2018). Ambas etnografías dan cuenta de las prácticas del derecho laboral, pero en términos temporales, el primero realizó su trabajo de campo entre los años 1970 y 1972, y el segundo lo realizó durante los años 2009 y 2010. Es importante señalar que la segunda investigación utiliza información recabada durante el año que inicia la implementación de la actual reforma procesal laboral (RPL de ahora en adelante).

Ambas etnografías ponen énfasis en una característica que representa al espíritu del Código del Trabajo: Esto es que el CT opera en base al "principio tuitivo" (Guidotti, 2013). Este principio refiere a que este código tiene una serie de coordenadas legales, hechas para que los jueces estén habilitados para poder resolver a favor de los trabajadores en caso de tener dudas en un litigio. Esto es porque el CT reconoce que hay una asimetría de poder entre la parte empleada y la parte empleadora.

Dentro de los aspectos que podemos comparar entre las investigaciones, destaca que, durante el gobierno del presidente Salvador Allende, cuando los trabajadores acudían a los tribunales que procesaban causas laborales, estos eran presionados a conciliar con la parte empleadora, a través de la acción de un funcionario llamado "el actuario". En este contexto, la labor del juez remite a ser un supervisor de las prácticas de sus subalternos, entre ellos, los actuarios y actuarias (letswaart, 1981). Esto era bastante útil para los jueces y juezas, pues en esta época la administración de los tribunales era su tarea y delegar algunas labores en otros, facilitaba poder llevar a cabo cumplir con las tareas prescritas a su cargo.

letswaart (1981) también sostiene que, cuando los trabajadores iban a tribunales sin la representación de un abogado, el actuario mostraba una abierta tendencia anti-trabajador, así como también una tendencia indiferente si el trabajador se presentaba con un abogado. En este sentido, el principio tuitivo brillaba por su ausencia, a pesar de su vigencia.

En cambio, en el caso de la RPL, el actuario como funcionario, fue eliminado, y ahora la judicatura fue liberada de varias tareas administrativas, y se ampliaron sus atribuciones para actuar en función del principio tuitivo. Rosado (2018) 
ejemplifica estas atribuciones a través varias notas etnográficas. Por ejemplo, en un caso donde se había demandado a un estudio de abogados, faltaban documentos para acreditar que el empleado había trabajado cinco años en este estudio. El juez exasperado por la falta de estos documentos, se tomó la libertad de citar a un oficial de corte del tribunal que antes trabajó en ese estudio. Con la información recabada pudo tener más claros los antecedentes del caso. No deja de ser relevante que, en este caso, no se logra una sentencia a favor del empleado, sino que se facilitó una conciliación en términos más favorables al trabajador a través de la presión que el juez le puso a la parte empleadora.

Es relevante decir que la etnografía de Rosado (2018) concluye sosteniendo que el principio tuitivo se ejerce a cabalidad. Esto significa que los jueces persiguen tener máxima claridad de los casos para que, si llegan a usar este principio, estos tengan la certeza de que no están usándolo caprichosamente. A esto se refiere Rosado (2018) cuando dice que en los tribunales laborales chilenos se cumple el imperio de la ley.

De ambos textos se puede concluir que los personajes más relevantes de cada periodo son los actuarios en el trabajo de letswaart (1981) y los jueces en el de Rosado (2018). Mientras los primeros presionaban a los trabajadores para conciliar, los segundos están orientados a cumplir el espíritu del CT. ¿Cómo será la situación ahora? ¿Qué se habrá mantenido en el tiempo? ¿Qué habrá cambiado?

\section{La temporalidad y el espacio de los tribunales laborales}

Con respecto al tiempo, tanto uno/a de los jueces/as y uno/a de los/las encargados de sala entrevistados/as señalan que la situación de judicialización de casos ha tenido una sostenida alza. De hecho, el/la juez/a 1, señala que actualmente están sobrecargados de trabajo. Si uno revisa los datos estadísticos entregados por el Poder Judicial de Chile (2018), se observa que la impresión de un alza no es una interpretación caprichosa de los actores y actoras. Durante el 2010 ingresaron 40375 casos y en el año 2017 ingresaron 72 247. Esto indica que, desde el inicio de la reforma, se ha visto una sostenida alza en la cantidad de contiendas que terminan siendo judicializadas. Sin embargo, la forma en que terminan estas contiendas ha tenido cambios en el tiempo. En el año 2010, hubo 12000 sentencias y 13000 conciliaciones. En cambio, en el 2017 hubo 16000 sentencias y casi 25000 conciliaciones ${ }^{1}$.

Desde lo anterior, es importante señalar dos aspectos que serán relevantes a la hora de realizar las conclusiones. Por un lado, estos datos estadísticos no pue-

\footnotetext{
${ }^{1}$ Los datos entregados por el Poder judicial no señalan el número exacto, sino un gráfico de ba-
} rras que permite aproximar los resultados. 
den tomarse del todo como representativos de los tribunales estudiados, ya que estos datos son del total de tribunales laborales en Chile, y no de los dos tribunales investigados. En segundo lugar, es interesante observar que la etnografía realizada por Rosado (2018) fue llevada a cabo durante el inicio de la implementación de la RPL, así como la que estoy haciendo aquí se redactó a comienzos del 2020. Esto permite comparar el inicio de la RPL con su actualidad.

Con respecto a los espacios dónde ocurre el derecho laboral, hay dos lugares que pude observar con detalle. Los primeros son los pasillos. A este lugar llegan las partes empleadoras y empleadas de los juicios, encontrándose cara a cara. En este espacio se pueden ver interacciones de diversa índole, pero destaca, para este artículo, aquellas negociaciones que se dan entre las partes presentes. En general, nunca se dan entre las partes afectadas, sino entre los abogados y abogadas representantes de cada lado de la contienda. Desde esa mirada, son lugares donde se da gran parte del proceso judicial, pues varias veces los casos llegan a la sala de audiencia "resueltos" por lo que pasa en los pasillos.

Desde lo anterior, el segundo lugar relevante, son las salas de audiencia (ver figuras 1 y 2 ).

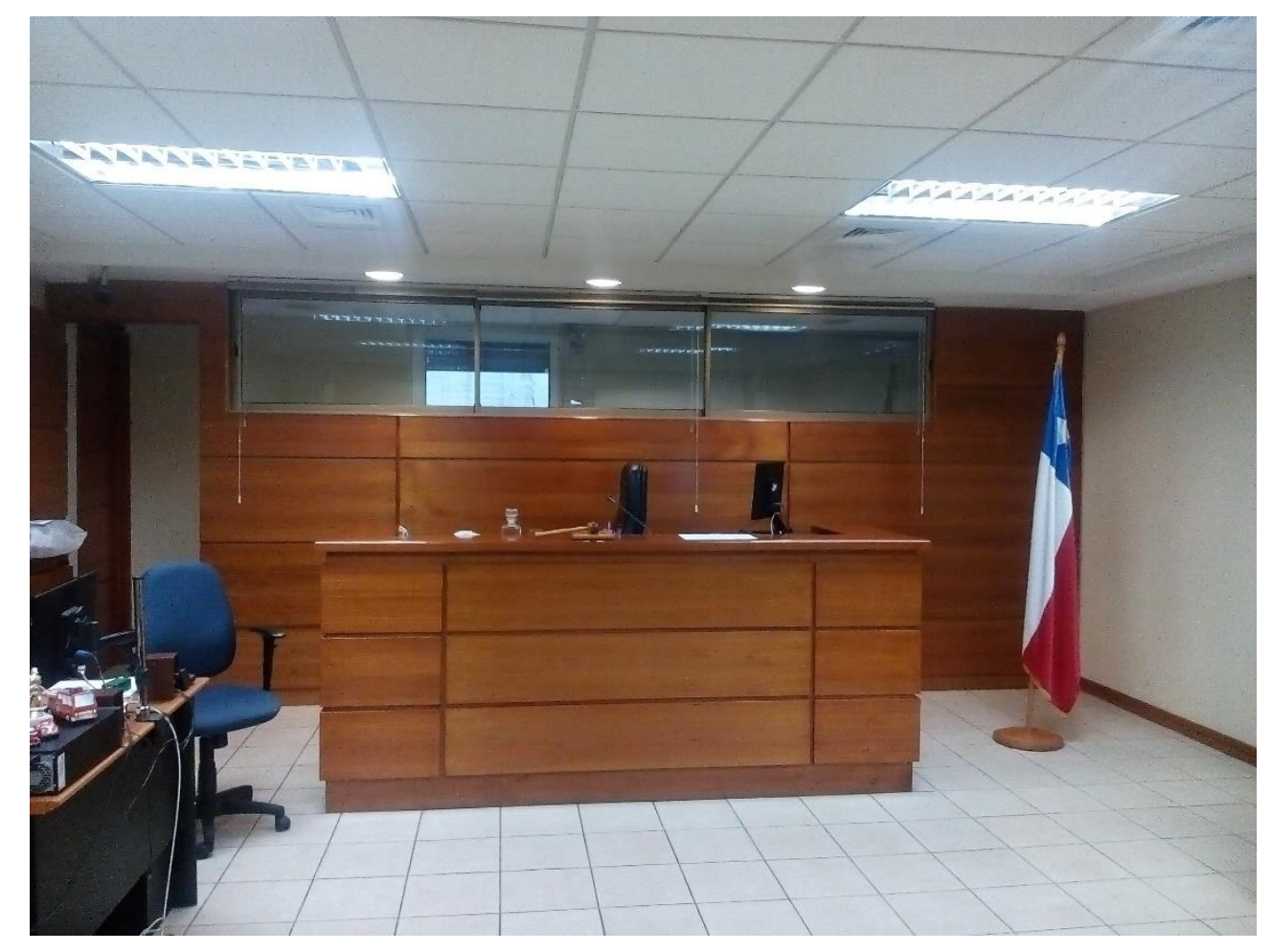

Figura 1. Fotografía de las salas de audiencia judicial desde la mirada del espectador 


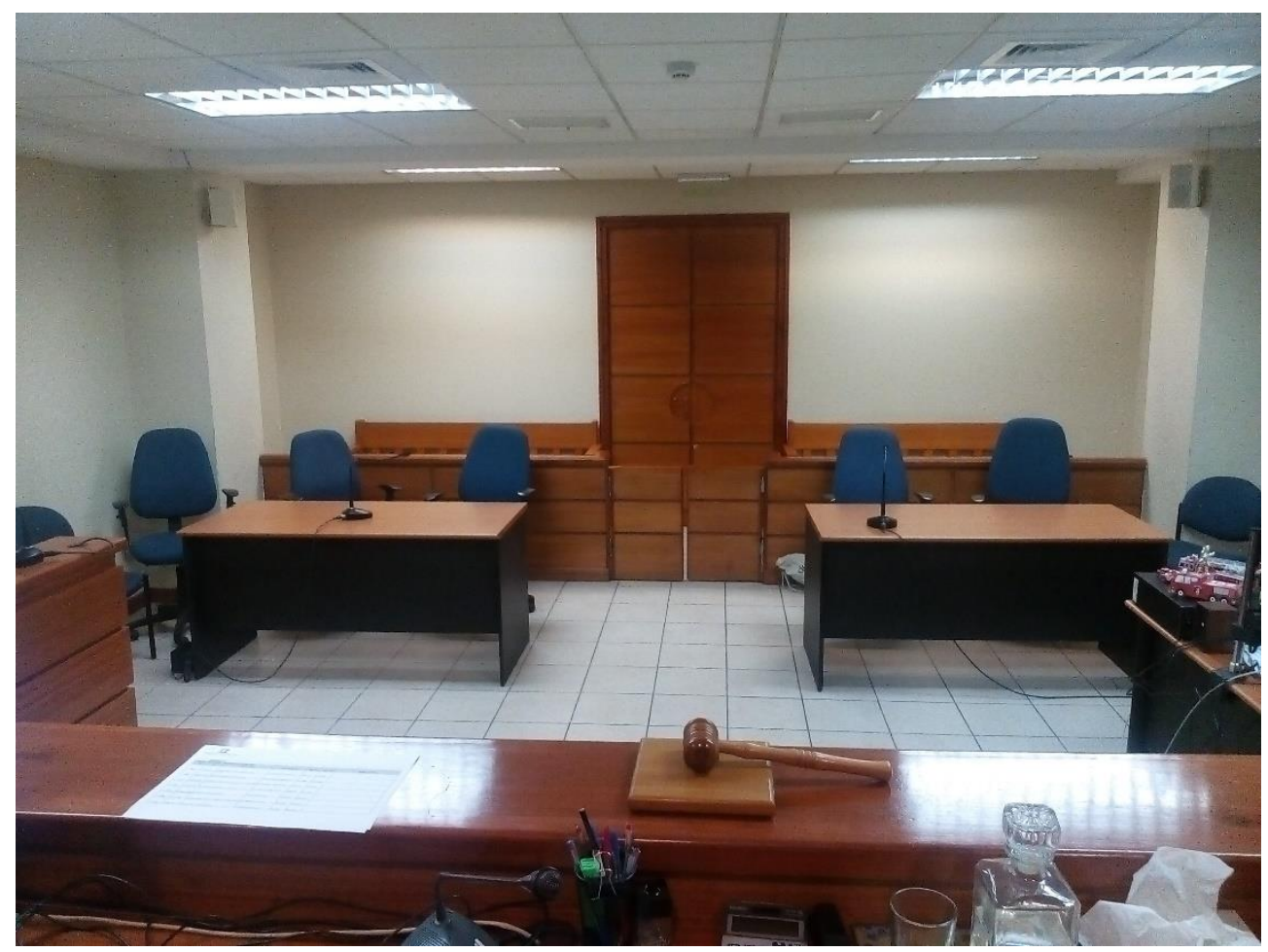

Figura 2. Fotografía de las salas de audiencia judicial desde la mirada del juez o jueza

Al comienzo de las observaciones, entré a una sala al azar. Ahí reconocí estos espacios. Entré a una "audiencia preparatoria". ¿Qué era una audiencia preparatoria? Le pregunté a un abogado, y me dijo - de modo no tan amable- "mira, todo eso, está en el Código del Trabajo” (CT en adelante). Desde ahí, entiendo que un proceso judicial laboral tiene varias etapas, las cuales son:

I. Ingreso de la demanda: este paso ocurre cuando un/a abogado/a sube la demanda de la parte demandante a la página web. En este momento, un/a juez/a tiene que evaluar si la demanda cumple con los requisitos para estar ajustada a derecho. Esto significa, en concreto, que las fechas datadas en la demanda cumplan con los señalamientos legales. Si la demanda está ajustada al CT, entonces se notifica a la parte demandada y se cita a una audiencia preparatoria.

II. Audiencia Preparatoria: Es una audiencia en la que los/as abogados/as llevan o exigen las evidencias a utilizar. Llevan la documentación recopilada (fotos, correos, mensajes de whatsapp, contratos, boletas, etc.) y una lista de nombres para que estos sean testigos/as del caso. También pueden exigir que algunos documentos llamados "oficios" sean pedidos por el tribunal para usarlos en el caso. Estos documentos provienen de instituciones a las que el ciudadano común no tiene fácil acceso, tales como la Superintendencia de 
Seguridad Social (SUSESO) o la Comisión de Medicina Preventiva e Invalidez (COMPIN). Es importante señalar que los/as abogados/as revisan la documentación de la contraparte, para ver si es factible objetar la evidencia, y evitar su uso en la audiencia de juicio. Finalmente, antes de empezar la revisión de estos documentos, el/la juez/a realiza un "llamado a conciliación" para verificar si las partes desisten de judicializar su contienda. Si las partes aceptan la conciliación, solo resta redactar un documento que acredite judicialmente el final de la contienda.

III. Audiencia de juicio: Si en la fase anterior no se logra una conciliación, se cita a una audiencia de juicio. En esta audiencia, los abogados presentan oficialmente todas sus pruebas, realizan interrogatorios a los/as testigos/as y se hacen las apreciaciones del caso. El/la juez/a monitorea y regula el procedimiento de estos profesionales durante el juicio. Finalmente, se anuncia una fecha en la que estará publicada la resolución judicial del caso.

IV. Redacción de la sentencia: En esta fase, el/la juez/a tiene un plazo de máximo dos semanas para redactar la sentencia del caso y subirla a la página web.

Observando estas audiencias, dando cuenta de cómo distintos actores se relacioban con los jueces, es que podemos armar este actor-red. A continuación, daré cuenta de la tendencia a la conciliación organizada alrededor de estos actores.

\section{La tendencia a la conciliación}

Tal como su nombre indica, esta tendencia refiere a que en tribunales hay toda una serie de actantes que generalmente logran ensamblarse para producir conciliaciones. No es que todos los casos terminen en acuerdos, pero sí es claro que una mayoría de los casos cierra en esto. ¿Cómo se produce esta tendencia? A continuación, se revisará las tres dimensiones de interconexión entre actantes que se registró.

\section{Las leyes y sus directrices entrecruzadas}

Los primeros actantes a analizar son las leyes. Estas son tomadas como una dimensión específica, pues refieren a actantes producidos fuera del Poder Judicial, pero que circulan desde el poder legislativo hasta los tribunales. Esto amerita ponerlos en una dimensión distina a la de los demás actantes observados directamente.

Como ya se dijo, el CT es una ley que organiza al derecho laboral. De hecho, cuando se le preguntó a un juez/a sobre qué objeto era imprecindible para llevar a cabo su acción, tomó con sus manos un libro del Código del Trabajo, y di- 
jo "en la dialéctica que es el proceso [judicial], el juez corta el queque ${ }^{2}$ con una herramienta que se llama la ley" (Juez/a 3, entrevista personal, enero del 2020). Sin embargo, resulta extraño que, si esta ley opera desde el principio tuitivo, yo haya visto tan pocos juicios en que el caso se resuelve con una sentencia a favor del trabajador/a. Una pista para poder resolver esta extrañeza apareció cuando, en una observación de pasillo, le comento sobre este tema a una abogada. Ella me responde "ah, es que eso está en el CPC". ¿Qué es el "CPC"? Es el Código de Procedimiento Civil. ¿Pero cómo puede operar esta ley -el CPC - con respecto al CT? El CT sostiene en su artículo 423 que "En todo lo no regulado en este Código o en leyes especiales, serán aplicables supletoriamente las normas contenidas en los Libros I y II del Código de Procedimiento Civil” (Ley N¹8620, 2002).

La aparición de este nuevo actante me lleva a leer esta ley y textos sobre ésta. Ahí encontré que esta ley opera con una facultad, que es la de la autonomía de la voluntad. Esta facultad se entiende de este modo: "las obligaciones nacen, ya del concurso real de las voluntades de dos o más personas, como los contratos o convenciones" (Romanik, 2014, p. 7). Esto significa que, en un juicio civil, si las partes llegan a un acuerdo, el proceso alcanza su clímax, restando solo redactar un documento que lo certifica legalmente. Esto puede pasar en cualquier momento del procedimiento. En una entrevista, una abogada sostiene que esto es problemático por lo siguiente:

El derecho laboral viene a proteger a la parte más débil y por eso existe ese quiebre entre el derecho civil y el derecho laboral. En derecho civil contratamos dos personas con una capacidad de negociación similar 'oye te contrato estos servicios, oye si porque yo trabajo los lunes no porque, esto es una prestación de servicios liberal, yo veo cuando los presto, lo que tenemos que ver es cuál va a ser el resultado'. En cambio, en el derecho laboral uno no negocia así y, es más, muchas veces el trabajador, si es que tiene esa capacidad de negociar, no lo hace porque se va a quedar sin el trabajo, o sea, yo prefiero sí firmar, págueme menos, puedo reclamar, pero prefiero estar con un trabajo en vez de no tener nada. (Abogada 2, entrevista personal, octubre del 2018)

Desde esa mirada, el que subrepticiamente esté el CPC operando como actante, tensiona el espíritu del CT. El principio tuitivo, nivelador de la asimetría choca con una ley que entiende a los contendientes como iguales. Desde lo anterior, y siguiendo a Zambrano (2015), dependiendo de las orientaciones ideo-

2 "Cortar el queque" es una expresión usada en Chile para señalar que la persona que corta el queque es aquella que toma las decisiones importantes, distribuyendo y organizando las acciones a discreción. 
lógicas de los jueces, estos tienen la posibilidad de escoger a escondidas su modo de resolver desde una mirada que beneficie al trabajador o al empleador.

No obstante, no me queda claro que los jueces decidan en relación a sus creencias ideológicas. $\mathrm{Ni}$ en las entrevistas ni en las observaciones vi algo que me llevara a sostener que las orientaciones de los jueces fueran suficiente como para montar la decisión hacia esas direcciones. Para profundizar en esta observación, es importante recordar otro encuentro con un abogado en el pasillo. Hablaban sobre un caso que había terminado en conciliación (antes de ver lo recurrente que eran), y desde ahí éste dice: "Recuerda que a ellos [los jueces] los evalúan por rendimiento" al mismo tiempo que hacía un gesto con el que se sobaba sus dedos pulgar, índice y cordial (el gesto que interpreto como que la conciliación permite aumentar el ingreso económico). Aquí es cuando aparece el Código Orgánico de Tribunales (COT de ahora en adelante). Esta ley organiza cómo funcionan los tribunales en un sentido jurídicoadministrativo. En ella, se dice que los jueces laborales son evaluados por los jueces de la Corte de Apelaciones (Ley N. ${ }^{\circ} 7421$ ), la cual es una corte de jerarquía superior a los tribunales laborales. En el artículo 277 bis del COT, se sostiene que esta evaluación se realiza en función de varias variables, pero las más relevantes son "responsabilidad y eficiencia". Desde ahí, la mezcla de estas tres leyes va configurando un tri-actante sobre el cual se sostiene la denominada "tendencia a la conciliación".

Ahora, es importante decir que no se me informó que los incentivos para los jueces/as fueran a través de dinero, sino a través de promociones. Retomaremos este aspecto en la segunda dimensión de actantes de la tendencia a la conciliación. De momento, lo relevante es decir que el CT, el CPC y COT se cruzan de tal modo que el primero permite la intromisión del segundo, y éste facilita lograr mejores indicadores en la evaluación que exige el tercero. De este modo, se hace razonable pensar junto a Vicente Sisto y Víctor Zelaya (2013), a propósito de la influencia del management en las lógicas de las instituciones públicas. El dispositivo de la evaluación parece tener injerencia con respecto a disponer la acción de los agentes (Sisto y Zelaya, 2013; Ramos, 2016). Es importante señalar que, para Ramos (2016), no es que la evaluación sistemáticamente facilite que los actores se muevan de acuerdo a lograr indicadores, pero dependiendo del uso que se le dé a la evaluación esto puede ocurrir. Para poder mostrar este uso, es necesario pasar a la siguiente dimensión. 


\section{La colaboración de los actantes directos}

Cuando se usa el concepto de "colaboración", refiere a cómo distintos actantes directamente observables realizan diferentes acciones, pero estas terminan coordinándose de tal modo que facilitan el mismo final: la conciliación. ¿Cuáles son estos actantes observados? ¿en qué sentido participan de esta tendencia?

Los primeros son los/as Jueces/as de jerarquías superiores ${ }^{3}$ : Como ya se dijo, la Corte de Apelaciones evalúa a los jueces de la corte laboral. De los/as jueces/as entrevistados/as, se observa que no hay resistencia a que su trabajo sea evaluado. "Eso es garantía para los ciudadanos" (Juez/a 3, entrevista personal, enero del 2020). Sin embargo, se observan problemas con el hecho de que quién evalúa jurisdiccionalmente, también interviene con la carrera profesional del juez o jueza. "Si soy un juez muy díscolo, aunque mi posición jurídica sea justificada, importante y moderna, probablemente amague mi carrera" (Juez/a 3 , entrevista personal, enero del 2020). En relación a esto, existe un rito llamado "la visita". Esta es descrita como "una institución medieval, donde el superior burócrata iba y revisaba qué hacían los jueces, para que no estuvieses fuera de la conducta de lo que el rey esperaba" (Juez/a 3, entrevista personal, enero del 2020). Desde ahí, hubo una visita donde un presidente de la corte suprema instó a los jueces a imitar los indicadores de conciliación que los juzgados laborales venezolanos tenían (alrededor de un $85 \%$ del total de resoluciones).

Desde lo anterior, el problema está en la forma en que los agentes de las cortes superiores actúan, presentándose como fomentadores de la búsqueda de conciliaciones.

Otros actores relevantes son los encargados y encargadas de sala. Con respecto a las conciliaciones, estos agentes las facilitan de dos modos. El primero de ellos refiere al anuncio de la expectativa naturalizada de la conciliación. Es usual que, antes de comenzar el juicio, salga de la sala este o esta personaje y diga: "las partes del caso X contra Z". Una vez reunidas las partes, lo primero que tienden a decir es “¿Ya tienen un acuerdo?”. Este gesto marca que desde adentro de la sala de audiencia, esperan que las partes lleguen a la sala con un acuerdo.

En segundo lugar, los encargados de sala facilitan cálculos para la conciliación (Moretti y Grudechut, 2019). En una ocasión, observé una audiencia en que la posible conciliación estaba trabada, pues la parte demandada no podía dar lo que la parte demandante exigía. El juez/a estaba a punto de comenzar ofi-

${ }^{3}$ No he visitado a los tribunales de orden superior, por lo que se dice sobre estos espacios, refiere exclusivamente a lo dicho por los/as entrevistados/as. 
cialmente el juicio. En ese instante el/la funcionario/a, se acerca sutilmente a la parte demandada y le dice: “ ¿Y si lo pagamos en tres cheques?”. En ese instante, el funcionario resolvió la conciliación.

Otro de los protagonistas son los jueces y juezas Dentro de las acciones de los jueces que fomentan la conciliación, se incluye la misma facilitación de cálculos de los/as actas, pero también incluyen toda una serie de enunciados conciliantes orientados a disponer a las partes a un arreglo. Dentro de los enunciados vistos, se ha reconocido los siguientes tipos:

1. Infantilización: En una audiencia preparatoria, escuché a un juez/a decirle a las partes: “¿Ya están grandes como para poder negociar, no?” apelando al adultocentrismo (Duarte, 2012), usando de modo peyorativo la noción de niñez implícita en el enunciado.

2. Uso de fechas conmemorativas: En otra audiencia, oí decir "Hagamos un esfuerzo. Hoy es navidad", apelando a que el espíritu de la época del año disuada la contienda.

3. Amenazas: También escuché "Yo que usted no seguiría, porque podría tener que pagar las costas si continúa”, apelando al temor a perder el caso.

4. Persuasión retórica: apelando a que las partes entiendan las limitaciones de lo que es posible conseguir en tribunales, vi a un/a juez/a diciendo " $\mathrm{Da}$ do que usted ya firmó el finiquito, lo que usted quiere no se puede dar por vía judicial. Debió haber consultado con sus abogados. En este caso, creo que lo mejor es que tratemos de llegar a una conciliación".

Es importante señalar en este punto que, a partir de lo anterior, es claro que puede haber razones fundadas para que una conciliación sea una salida justificada si uno quiere defender a la parte demandante.

También los bogados y abogadas participan de producir esta tendencia a través de la resignificación proconciliadora. A través de conversaciones en voz baja, mensajes de whatsapp (cuando las partes están fuera de la sala o del tribunal) o saliendo a conversar con los involucrados al pasillo, estos agentes traducen en nuevos registros lo que ocurre dentro de la sala de audiencia, para así lograr la conciliación. He observado dos tipos de estas resignificaciones:

1. Recalibración de significados: en un caso, para conciliar, la parte demandante quería 13 millones de pesos. La parte demandada ofrecía 9,5 millones. El abogado salió a conversar con el trabajador y le dijo: "Es mejor aceptar, porque 9,5 millones por un caso como éste es mucha plata"

\footnotetext{
${ }^{4}$ En Chile se le llama "plata” al dinero.
} 
2. Atemorizar: en un caso, un trabajador no quería conciliar. Salió al pasillo a conversar con el abogado y al volver se aceptó la conciliación. Al terminar la audiencia, le pregunté al trabajador sobre qué hablaron y me dijo "El abogado me explicó que si no aceptábamos la propuesta del juez, puede que después el juez se enoje y falle en nuestra contra".

Finalmente, los últimos actantes observados son los documentos digitales prellenados. Latour $(2005 / 2008)$ señala que, para observar la acción de los objetos no humanos, se puede ver qué ocurre cuando no están presentes. Hubo un caso entre un sindicato y una empresa en la que, después de una discusion, las partes decidieron llegar a una conciliación. Es importante señalar que los abogados del caso decían que este era "un caso muy extraño", pues casi no hay conciliaciones en los casos sindicales. Por esto, no había un documento digital prellenado que facilitara la escritura de la conciliación. Desde ahí, vi cómo los/as abogados/as de ambas partes le dictaban los aspectos que tenía que tener el acuerdo a el/la encargado/a de sala. El acuerdo varias veces estuvo por desensamblarse, pues había grandes desacuerdos con respecto a qué debía incluir el documento que legitimara la conciliación. En ese sentido, estos documentos facilitan una vía expedita post-acuerdo, evitando que la conciliación acordada se debilite.

\section{La afectividad de los actantes}

Finalmente, está el cómo el cuerpo es afectado por los entramados con los que se vincula en el derecho laboral. Las afecciones que se revisarán acá son aquellas que participan de promover la tendencia a la conciliación.

Por un lado, es claro que la inseguridad aparece con claridad en lo ya he descrito hasta aquí. Muchas de las acciones de los agentes judiciales producen este afecto. Es gracias a la inseguridad con respecto a perder el juicio que las partes tienden a conciliar, cuando los jueces o los abogados señalan que la posibilidad de perder está presente si se continúa con el caso. David Knights y Caroline Clarke (2013) estudian la inseguridad en el contexto del trabajo académico. En este estudio, se muestra que la inseguridad facilita que la vivencia de los académicos sea experimentada como un sentimiento ambivalente, dulce y amargo al mismo tiempo (Knights y Clarke, 2013). En este sentido, el afecto que aparece al saber que no se obtendrá lo querido en el caso, pero que al mismo tiempo se recibirá algo que no se tendría si no se hubiese pasado por una audiencia judicial, da cuenta de un sentir que promueve un malestar que se suaviza en razón de algo más "dulce". A esto, le podemos llamar "inseguridad conciliante". 
Lo anterior, daría cuenta de los afectos que promueven la conciliación en las partes. No obstante, hay otro afecto que participa de jueces y juezas de una manera importante: la angustia. Observemos una nota etnográfica:

En una audiencia de juicio sobre acoso sexual, la parte demandante recibe una oferta de conciliación. Piden salir, y el/la juez/a toma un receso. Mientras la demandante y el abogado conversan en el pasillo, el/la juez/a dice "ojalá acepte. Para este caso la ley no sirve, y yo sólo puedo declarar incompetencia. ¡No tiene sentido! ¡No tiene sentido! ¡No tiene sentido!” (Entrada de diario de campo, abril de 2019)

Antes de analizar esta nota, veamos qué se puede decir de la angustia. En otro artículo, trabajé cómo la filosofía de Søren Kierkegaard sobre la angustia puede ser utilizada en el campo de las ciencias sociales (Grudechut, 2020). Para este autor, en términos generales, la angustia "es la realidad de la libertad como posibilidad antes de la posibilidad" (Kierkegaard, en Grudechut, 2020, p. 78), lo que significa que este afecto aparece cuando los sujetos pueden optar libremente por alguna posibilidad, dando la oportunidad de hacerse responsable de construir el camino al futuro. Sin embargo, dado el vértigo que puede producir vivir orientado a un futuro incierto, una de las formas de evadir superficialmente - este afecto es la de cosificar el porvenir. Esto supone que el futuro está predeterminado lógicamente y que la participación humana sobre la construcción del desarrollo humano es prescindible (Grudechut, 2020). Esta visión mecánica del futuro está socialmente construida y la afectividad desarrollada con ella está mediada por la expectativa construida de que el futuro no necesita de la acción humana.

Desde lo anterior, la angustia parece realizarse en el cuerpo de los/as jueces/as. A propósito del caso, es importante decir que el CT tiene varios artículos con los cuáles se puede tomar decisiones con respecto a la temática del acoso sexual. Sin embargo, el/la juez/a reacciona como si encontrara un sin sentido tomar una decisión, incluso habiendo una mujer que está en una contienda por defender sus derechos fundamentales. El/la juez/a prefiere que las partes concilien para que así ella no tenga que hacerse cargo del futuro de estas partes. Además, el/ella actúa de acuerdo a la forma "lógica" instalada en la cotidianidad del tribunal, es decir, se ensambla bajo la lógica de la conciliación. Esto favorece que las conciliaciones se reproduzcan desde la misma subjetividad de los actantes humanos. De este modo, parece ser que la conciliación es una práctica orientada a evitar el vértigo de la angustia en tribunales, pues se ha constituido como el modo "lógico", o mejor dicho naturalizado, de operar en tribunales. 
Es relevante decir que esto amerita indagarse más, pues no he podido indagar directamente acerca de este afecto a través de entrevistas, pero no deja de ser interesante que el movimiento de los jueces y juezas tiende a la evitación de la toma de posición cuando el caso se acerca a que se les exija tener que tomar una posición. Esta crítica a la falta de toma de posición es usual en tribunales (Atria, 2004; Feierstein, 2012), pero usualmente se le asocia al positivismo jurídico un vínculo causal. Yo no estoy en desacuerdo con esa hipótesis, pero creo que es relevante también remarcar la complejidad del fenómeno y poner énfasis en la dinámica afectiva que lleva a la desresponsabilización en la acción de los/as jueces/as.

En la tabla 2 se bosqueja una tabla que permite sintetizar los distintos procesos revisados y analizados con respecto a la tendencia a la conciliación.

\begin{tabular}{ll}
\hline \multicolumn{2}{l}{ Actantes que sostienen a la tendencia a la conciliación } \\
\hline \multirow{2}{*}{ Leyes } & Código del trabajo \\
& Código de Procedigo Orgánico de Tribunales \\
\hline & Jueces y juezas de Juzgados Superiores \\
Actantes in & $\begin{array}{l}\text { Encargados y encargadas de Sala } \\
\text { situ }\end{array}$ \\
& $\begin{array}{l}\text { Jueces y juezas del Juzgado Laboral } \\
\text { Abogados y abogadas }\end{array}$ \\
\hline \multirow{2}{*}{ Afectos } & Inseguridad \\
& Angustia \\
\hline
\end{tabular}

Tabla 2. Síntesis de actante que promueven la tendencia la conciliación

\section{CONCLUSIONES}

¿Cómo funciona la relación entre el contexto laboral del derecho laboral con el trabajo de los jueces y juezas? Sin poder detectar una clara causalidad, resulta evidente que al menos hay una correlación en que el derecho laboral tenderá a defender mejor los intereses de los trabajadores, en la medida en que los jueces estén liberados de altas cargas de trabajo. En el trabajo de lestwaart (1981), los actuarios se orientaban a forzar conciliaciones entre empleados y empleadoras, y los jueces se dedicaban a supervisar, entre otras múltiples tareas, incluyendo las problemáticas administrativas del tribunal. La situación pareció mejorar cuando se le dejó a los jueces sólo las tareas que refieren al impartir el derecho. Esto facilitó, en palabras de Rosado (2018), proteger el 
imperio de la ley y así al principio tuituvo del Código del Trabajo. Pero en la actualidad, el forzar la conciliación se volvió el modo regular de asociación entre actantes. Si bien, en la actualidad, los jueces no han vuelto a tener que realizar trabajo administrativo, el alza en la judicialización de controversias laborales parece disponer la producción de conciliaciones.

Una diferencia importante con respecto al funcionamiento entre la etnografía de letswaart (1981) y ésta, es que no se observa abiertamente la aparición de una tendencia antitrabajador en los tribunales actuales. Desde ese punto, esto reafirma que la alta taza de conciliaciones no está dada por los agentes del tribunal como una práctica que está abiertamente en contra del principio reequilibrador entre empleador y empleado (el principio tuitivo), sino que se realiza como un medio para poder lograr, tanto la posibilidad de movilidad a tribunales de mayor categoría, como la rebaja de carga laboral. En ese sentido, desde la gestión del trabajo judicial, se facilita el desarrollo de una actitud indiferente frente al trabajador. Esto, aunque parece mejor, puede ser un problema, pues como se puede leer desde Hugo Rojas (2015), la indiferencia es una actitud que tradicionalmente pavimenta la negación del otro como sujeto de derecho.

Una segunda conclusión refiere a la construcción de la tendencia a la conciliación. Desde la TAR, observamos que, desde tres dimensiones de actantes, se produce un ensamblaje de elementos heterogéneos que disponen que esta tendencia se realice. La dimensión jurídica, al producir las leyes, dispone un marco de movimientos específicos para los actores y actoras de los tribunales laborales. Por la forma en que se intersectan las leyes, van acotando las posibilidades de acción de los agentes, de tal modo que el movimiento de los actantes tiende a colaborar hacia la meta de producir acuerdos. Esta retroalimentación que la acción de los actantes sostiene, a propósito de las intersecciones legales, dispone que se repita el modo de actuar conciliante. Esto conlleva a que los cuerpos se habitúen a esta lógica, construyendo afectividades que están al servicio de producir y reproducir acuerdos. La angustia observada es señal de lo anterior. Esto es interesante, pues permite observar la relación entre la macrofísica y la microfísica de los tribunales laborales.

Es importante no concluir que esta tendencia a la conciliación es efectivamente causada por alguno de los actores que participan de esta red, en especial encargados/as de sala o de jueces/as de cortes superiores. Estos actores y actoras también son parte de otros espacios de las redes de asociación entre actantes. En ese sentido, no se puede asumir como conclusión que estos actores disponen la tendencia. Desde este aspecto, se hace relevante investigar cómo se articulan las redes en relación a estos actantes y preguntarse, por ejemplo, 
¿Cómo se desarrolla el proceso por el cual los jueces de cortes superiores buscan promover las conciliaciones?

Para terminar, referiré al devenir histórico de los tribunales laborales. El derecho laboral nace como instancia de mediación pacífica entre empleados y empleadores (Valenzuela, 2008). En su momento fue muy críticado, pues se decía que el Estado estaba cooptando al movimiento de los trabajadores, debilitando sus posibilidades con respecto a la acción organizada (Valenzuela, 2008). A lo largo del proceso, una actitud pro-trabajador sólo se ha visto en la breve experiencia registrada por Rosado (2018). Esto permite reabrir la pregunta por la pertinencia del derecho laboral. ¿Tendrá razón esta crítica? ¿Será mejor dejar en manos de los trabajadores su defensa frente a los empleadores? ¿O bastará con transformar los modos de gestión de lo judicial? Personalmente, creo que aún los tribunales laborales tienen algo que decir, pues la diferencia de poder entre trabajadores y empleadores es grande en un pais como Chile. Por lo mismo, se hace urgente facilitar modos de organización que hagan posible que los tribunales puedan mantener en pie el espíritu que los hizo nacer. Y, quizás así, puedan defender mejor a los trabajadores en su individualidad o, mejor aún, que aparezcan con mayor frecuencia los sindicatos en los tribunales.

\section{REFERENCIAS}

Atria, Fernando (2004). La ironía del positivismo jurídico. DOXA, Cuadernos de Filosofía del Derecho, 27, 81-139. https://doi.org/10.14198/DOXA2004.27.05

Barrera, Leticia (2012). La Corte Suprema en escena: Una etnografía del mundo judicial. Siglo XXI.

Bernick, E. Lee \& Pratto, David J. (1995). A behavior-based evaluation instrument for judges. Justice System Journal, 18(2), 173-184.

https://www.jstor.org/stable/27976898

Brody, David (2000). Judicial performance evaluations by state governments: Informing the public while avoiding the pitfalls. The Justice System Journal, 21(3), 333-

347. https://www.jstor.org/stable/27977038

Brody, David (2008-2009). The use of judicial performance evaluation to enhance judicial accountability, judicial independence, and public trust. Denver University Law Re-view, 86(1), 115-156. https://www.law.du.edu/documents/denver-universitylaw-review/v86_i1_brody.pdf

Burawoy, Michael (1998). The extended case method. Sociological Theory, 16(1), 4-33. https://doi.org/10.1111/0735-2751.00040

Duarte, Claudio (2012). Sociedades Adultocéntricas. Sobre sus orígenes y su reproducción. Última Década, 20(36), 99-125. http://dx.doi.org/10.4067/S0718$\underline{22362012000100005}$

Feierstein, David (2012). Juicios. Sobre la elaboración del genocidio II. Fondo de Cultura Económica. 
Ferreira, Arthur Arruda Leal (2011). ¿Con cuántos dispositivos se produce una subjetividad? Athenea Digital, 11(1), 195-201. https://doi.org/10.5565/rev/athenead/v11n1.821

Garfinkel, Harold (1968/2006). Estudios en etnometodología. Anthropos.

Grudechut, Iván (2020). La angustia en los movimientos sociales: Una reflexión acerca del horizonte de la acción política. Castalia - Revista De Psicología De La Academia, 33, 71-87. https://doi.org/10.25074/07198051.33.1489

Guber, Rosana (2001/2011). La etnografía. Método, campo y reflexividad. Siglo XXI.

Guidotti, Boonie (2013). La igualdad y el principio protector en el proceso laboral. En Fernando Muñoz (Ed.), Igualdad, inclusión y derecho (pp. 153-164). LOM.

Hammersley, Martyn \& Atkinson, Paul (1994). Etnografía. Métodos de investigación. Paidós Ibérica.

letswaart, Heleen (1981). Labor relations Litigation: Chile, 1970-1972. Law \& Society Review, 16(4), 625-668. https://doi.org/10.2307/3053474

Knights, David \& Clarke, Caroline (2013). It's a bittersweet symphony, this life: Fragile academic selves and insecure identities at work. Organization Studies, 35(3), 335357. https: //doi.org/10.1177/0170840613508396

Latour, Bruno (2005/2008). Reensamblar lo social. Una introducción a la teoría del Actor-Red. Editorial Manantial.

Latour, Bruno (2002/2010). Making the law. An ethnography of the Conseil d'Etat. Polity Press.

Ley $\mathrm{N}^{\circ} 7421$ de 15 de junio de 1942. Código Orgánico de Tribunales. Santiago.

Ley $\mathrm{N}^{\circ} 18620$ de 31 de julio de 2002. Código del Trabajo. Decreto con Fuerza de Ley $N^{\circ}$ 1, Fija Texto Refundido, Coordinado y Sistematizado del Código del Trabajo. Santiago.

Montt, María Eugenia (2016). Apuntes de Derecho Procesal Laboral. Revista Chilena de Derecho del Trabajo y de la Seguridad Social, 3(6), 233-245.

https: //doi.org/10.5354/0719-7551.2016.42863

Moretti, Renato \& Grudechut, Iván (2019, agosto). Quantification, Psychology and Law: A Comparison Between Expertises. En P. Stenner (Presidencia), 18th biennial conference of International Society for Theoretical Psychology is: Measured Lives Theoretical Psychology in an Era of Acceleration. Copenhagen, Dinamarca.

Poder Judicial de Chile (2018). Poder Judicial en Números 2017. Estadísticas de causas. https://www.pjud.cl/post/download/484

Ramos, Claudio (2008) ¿Sistema, campo de lucha o red de traducciones y asociaciones? Tres modelos para investigar la ciencia social y un intento de integración. Persona y Sociedad, 22(2), 9-52.

https://personaysociedad.uahurtado.cl/index.php/ps/article/view/161

Ramos, Claudio (2016). La producción de la pobreza como objeto de gobierno. Editorial Universidad Alberto Hurtado. 
Roach Anleu, Sharyn. \& Mack, Kathy (2016). Rendimiento Judicial y Experiencias del Trabajo Judicial: Hallazgos de la Investigación Socio-jurídica. Sortuz, 8(1), 77-104. http://opo.iisj.net/index.php/sortuz/article/view/808

Rojas, Hugo (2015). Indiferencia de los chilenos con respecto de las violaciones a los derechos humanos cometidas entre 1973 y 1990. Revista de derechos fundamentales, 13, 71-107. https://doctrina.vlex.cl/vid/indiferencia-chilenos-respecto-violaciones634893145

Romanik, Katy (2014). La voluntad de las partes en el contrato individual laboral. Análisis de algunas cláusulas especiales. https://www.dt.gob.cl/portal/1629/articles-103032_archivo_01.pdf

Rosado, César (2018). The Labor Judge Unleashed: Rule of Law and Labor Rights in “Neoliberal” Chile. Law \& Social Inquiry, 43(4), 1574-1603. https://doi.org/10.1111//si.12341

Sisto, Vicente \& Zelaya, Víctor (2013). La etnografía de dispositivos como herramienta de análisis y el estudio del managerialismo como práctica local. Universitas Psychologica, 12(4), 1345-1354. https://doi.org/10.11144/Javeriana.UPSY12-4.edha

Valenzuela, Humberto (2008). Historia del Movimiento Obrero Chileno. Editorial Quimantú.

Vargas, Juan Enrique (2007). Eficiencia en la justicia. Modelos y buenas prácticas en gestión judicial. En José Francisco García, Francisco Leturia \& Claudio Osorio (Eds.), Reforma al Poder Judicial: Gobierno Judicial, Corte Suprema y Gestión (pp. 251 289). Ediciones Libertad y Desarrollo.

Zambrano, Juan Pablo (2015). Derecho, Ideología y Discurso. Alpha (Osorno), 40, 7180. https://doi.org/10.4067/S0718-22012015000100006

IVÁN Esteban GRUdeChut PEZOA

Psicólogo, Magister en Psicología Social Comunitario y Doctor (c) en Sociología. Me interesan temas como la Educación de Adultos, la intervención social, la teoría social y la sociología judicial.

ivan.grudechut@gmail.com

https://orcid.org/0000-0002-6756-632X

\section{FORMATO DE CITACIÓN}

Grudechut Pezoa, Iván (2021). El trabajo de la judicatura laboral: directrices legales, colaboración y afectos. Quaderns de Psicologia, 23(2), e1608.

https://doi.org/10.5565/rev/qpsicologia. 1608 


\section{HISTORIA EDITORIAL}

Recibido: 20-01-2020

$1^{a}$ revisión: 25-02-2021

Aceptado: 23-07-2021

Publicado: 31-08-2021 